\title{
Spoken second language words activate native language orthographic information in late second language learners
}

\author{
OUTI VEIVO \\ University of Turku \\ VINCENT PORRETTA \\ University of Windsor \\ JUKKA HYÖNÄ \\ University of Turku \\ JUHANI JÄRVIKIVI \\ University of Alberta
}

Received: February 21, 2017 Accepted for publication: February 16, 2018

\section{ADDRESS FOR CORRESPONDENCE}

Outi Veivo, University of Turku, School of Languages and Translation Studies, 20014 University of

Turku, Finland. E-mail: outi.veivo@utu.fi

\begin{abstract}
This study investigated the time course of activation of orthographic information in spoken word recognition with two visual world eye-tracking experiments in a task where second language (L2) spoken word forms had to be matched with their printed referents. Participants $(n=64)$ were native Finnish learners of L2 French ranging from beginners to highly proficient. In Experiment 1, L2 targets (e.g., $<$ cidre $>/$ sidR/) were presented with either orthographically overlapping onset competitors (e.g., $<$ cintre $>/ s \tilde{s} \mathrm{tr} /)$ or phonologically overlapping onset competitors ( $<$ cycle $>/$ sikl/). In Experiment 2, L2 targets (e.g., < paume >/pom/) were associated with competitors in Finnish, L1 of the participants, in conditions symmetric to Experiment 1 (<pauhu>/pauhu/vs. <pommi $>$ /pom:i/). In the withinlanguage experiment (Experiment 1), the difference in target identification between the experimental conditions was not significant. In the between-language experiment (Experiment 2), orthographic information impacted the mapping more in lower proficiency learners, and this effect was observed $600 \mathrm{~ms}$ after the target word onset. The influence of proficiency on the matching was nonlinear: proficiency impacted the mapping significantly more in the lower half of the proficiency scale in both experiments. These results are discussed in terms of coactivation of orthographic and phonological information in L2 spoken word recognition.
\end{abstract}

Keywords: eye tracking; first language effects; orthography; proficiency; second language; spoken word recognition; visual world paradigm 
There is a growing body of literature showing that just as phonological information is activated during the processing of written language (see, e.g., Frost, 1998, for a review), orthographic information is activated during the processing of spoken language (see Frost \& Ziegler, 2007, for a review). There are, however, fewer studies on the role of orthography in second language (L2) spoken word processing. In this study, we are interested in how L2 learners with a formal instruction background use orthographic information in spoken word recognition.

Late L2 learners differ from native language (L1) speakers because they already use one phonological system that can influence the learning of another system (e.g., Best \& Tyler, 2007), and because they are already familiar with the graphemephoneme correspondences of their L1, which can have a strong impact on the perception and learning of L2 sounds (Bassetti, 2006; Escudero, Hayes-Harb, \& Mitterer, 2008; Escudero \& Wanrooij, 2010; Hayes-Harb, Nicol, \& Barker, 2010; Showalter \& Hayes-Harb, 2015). In addition, unlike L1 speakers who learn orthographic word forms only after the phonological forms have been established, literate L2 learners in formal instruction are exposed to written word forms early on in the learning process. The present study investigated how these L2 learners map L2 spoken words onto their written counterparts, specifically the extent to which this mapping is mediated by orthographic or phonological information, and to which L1 grapheme-phoneme correspondences are activated in this process. For this purpose, we conducted two experiments where spoken word forms had to be matched with their printed referents while participants' eye movements were monitored. We also set out to evaluate the role of L2 proficiency in this matching process.

Even though orthographic information is not necessary in L1 spoken language processing, it is known to be activated even during (non-metaphonological) language processing tasks such as lexical decision that do not demand a special focus on the phonotactic or orthotactic structure of the word forms (Grainger, Diependaele, Spinelli, Ferrand, \& Farioli, 2003; Grainger \& Ferrand, 1996; Salverda \& Tanenhaus, 2010; Ventura, Morais, Pattamadilok, \& Kolinsky, 2004; Ziegler \& Ferrand, 1998, but see, e.g., Mitterer \& Reinisch, 2015, for the lack of orthographic effects in the perception of conversational speech). These orthographic effects have been explained by a simultaneous coactivation of phonological and orthographic representations (e.g., Grainger et al., 2003) or by an activation of orthographically restructured phonological representations (Taft, Castles, Davis, Lazendic, \& Nguyen-Hoan, 2008) during the processing of spoken words.

In the L1, the written forms of words are learned after their spoken forms, but in L2 instructed learning environments, the two modalities are learned in parallel. As a result of this co-structuration of orthographic and phonological information (Veivo \& Järvikivi, 2013), orthography may have a more important role in the L2 lexicon than in the L1 lexicon. Further, there is evidence that if the orthographic system of the L2 is incongruent (i.e., if the phonemes can be represented by several different graphemes or vice versa), parallel acquisition of orthography and phonology can be a hindrance to the acquisition of the L2 phonological system (Escudero, Simon, \& Mulak, 2014).

In L2 spoken word processing, the activation of orthographic information has been studied especially from the point of view of the parallel activation of the L1. For example, Bartolotti, Daniel, and Marian (2013) showed that during spoken 
word recognition in a newly acquired L2, orthographically similar L1 word forms are activated even if they are pronounced differently from the target words. This result is complementary to studies showing that phonologically similar words of both languages of bilingual or second language speakers compete for recognition in parallel (Blumenfeld \& Marian, 2007; Marian \& Spivey, 2003a, 2003b; Spivey \& Marian, 1999).

The role of orthographic input for the learning of L2 phonology has been widely studied (for reviews, see Bassetti, 2008; Young-Scholten, 2002). There is evidence that orthography can help to acquire new phonemic categories of the L2 (Escudero et al., 2008, 2014; Showalter \& Hayes-Harb, 2013; Simon, Chambless, \& Kickhöfel Alves, 2010), but can also have a negative impact on the acquisition of L2 phonology (Bassetti, 2007; Bassetti \& Atkinson, 2015; Young-Scholten \& Langer, 2015), especially when the grapheme-phoneme relations of the L2 are different from the L1 (Escudero \& Wanrooij, 2010; Hayes-Harb et al., 2010). Furthermore, there is evidence that late L2 learners in instructed learning environments can have an orthographic bias in their lexical knowledge, especially in the recognition of decontextualized word forms (Veivo, Suomela-Salmi, \& Järvikivi, 2015). At the same time, words for these learners can have imprecise phonological representations (Cook \& Gor, 2015; Cook, Pandža, Lancaster, \& Gor, 2016), which may lead not only to the activation of false semantic content (Cook et al., 2016) but also to increased lexical competition (Broersma \& Cutler, 2011).

If the phonological representations of L2 words are more imprecise and unstable than those for L1 words, they may also be less well connected to their orthographic counterparts. As proficiency in the L2 increases, phonological representations are likely to become more accurate (Darcy, Daidone, \& Kojima, 2013) and the orthographic bias in accessing semantic content decreases (Veivo et al., 2015). Taken together, the lexicon of late L2 learners in instructed learning could be orthographically biased so that orthographic representations may be more robust than phonological representations. Moreover, this relative bias might decrease as proficiency increases. In the present study, we evaluated this orthographic bias hypothesis by examining the flow of information from spoken word forms to written word forms in late L2 learners at different proficiency levels.

Previous studies have shown that proficiency can influence orthographic activation in L2 spoken word processing: orthographic information during spoken word processing is activated more rapidly and more strongly in more proficient than in less proficient L2 learners (Mitsugi, 2016; Veivo \& Järvikivi, 2013; Veivo, Järvikivi, Porretta, \& Hyönä, 2016). Specifically, Veivo et al. (2016) used the visual world paradigm with printed referents and observed a significant effect for the degree of orthographic overlap of the vowels in targets and competitors (target:

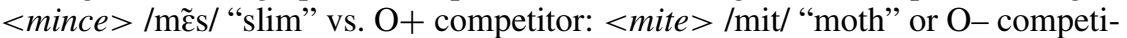
tor: <mythe >/mit/ "mythe"), but only for higher proficiency participants. This suggests that orthographic information modulates L2 spoken word identification at least for higher proficiency learners. However, Veivo et al. (2016) did not contrast the two types of within-language L2 competitors in the same experiment or investigate the activation of between-language competitors from the participants' L1 to evaluate the activation of L1 orthography in L2 spoken word processing. The present study was designed to fill this gap. 


\section{CURRENT STUDY}

In the present study, our main objectives were to investigate the mapping of spoken L2 words onto their written referents, and to evaluate whether this mapping is mediated mainly via orthographic or phonological information. For this purpose, we used the visual world eye-tracking paradigm (Allopenna, Magnuson, \& Tanenhaus, 1998; Cooper, 1974; Tanenhaus, Spivey-Knowlton, Eberhard, \& Sedivy, 1995; for a review, see Huettig, Rommers, \& Meyer, 2011) in a task where spoken words are matched with their written counterparts (cf. Huettig \& McQueen, 2007, 2011; McQueen \& Viebahn, 2007). We studied Finnish learners of French with a wide range of proficiency levels. The task in both experiments consisted of listening to spoken instructions in French ("cliquez sur le mot cidre") and clicking on one of the four words (target, competitor, and two unrelated distractors) that appeared on the computer screen $200 \mathrm{~ms}$ before the acoustic onset of the target word. The spoken target words were accompanied by a high orthographic low phonologi-

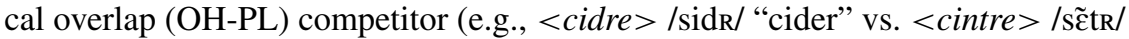
"coat hanger") or a low orthographic high phonological overlap (OL-PH) competitor (e.g., <cidre> /sidR/ vs. < cycle> /sik1/ "cycle") either in the L2 (Experiment 1) or in the L1 (Experiment 2).

If orthographic input in L2 acquisition leads to an orthographic bias in the lexical knowledge of late L2 learners (e.g., Young-Scholten, 2002; for a review, see Bassetti, 2008), we expect orthographically similar competitors to delay the mapping more than phonologically similar competitors. If the precision of phonological representations depends on proficiency (Darcy et al., 2013), proficiency will affect the speed of the mapping process. Based on previous results (Veivo \& Järvikivi, 2013), lower proficiency learners might activate sublexical graphemephoneme correspondences of the L1, which would show as increased activation of phonologically similar L1 competitors in Experiment 2.

We started by investigating in Experiment 1 the matching of French spoken and written L2 word forms in the presence of within-language orthographic and phonological competitors.

\section{EXPERIMENT 1}

\section{Method}

Participants. Sixty-four students from the University of Turku participated for course credit or volunteered. They reported no hearing impairment or language deficits and had normal or corrected-to-normal vision. All participants were native speakers of Finnish who had learned French as a foreign language in instructed learning. None of the participants had acquired French or any other language besides Finnish before the age of 3. Their age of onset for L2 French varied between 5 and 45 (median =14). This means that they were all either literate or had started to acquire literacy in their L1 when they began to learn the L2. The participants represented a wide range of proficiency levels ranging from beginners to highly proficient. They evaluated their proficiency in French for five subskills (listening, reading, spoken interaction, spoken production, and writing) with the CEFR self-assessment grid (2001, pp. 26-27). Each subskill was self-assessed 
Veivo et al.: L1 orthographic information in late L2 learners

Table 1. Background information for participants $(n=64)$ in Experiments 1 and 2.

\begin{tabular}{lrccc}
\hline \hline \multicolumn{1}{c}{ Background information } & $\min$ & $\max$ & mean & median \\
\hline Age (years) & 19 & 49 & 23.3 & 22 \\
Age of acquisition for French (years) & 5 & 45 & 15.6 & 14 \\
L2 proficiency & 5 & 28 & 16.3 & 17 \\
\hline
\end{tabular}

on six levels, which were assigned values from 1 to 6 . The maximum score for proficiency for each participant was therefore $30 .{ }^{1}$ Participant-related background information is summarized in Table $1 .^{2}$

Materials. The visual displays comprised four words: target, competitor, and two distractors. There were 20 target words (e.g., $<$ cidre $>$ ) each associated with either a OH-PL overlap competitor (e.g., <cintre $>$ ) or a OL-PH overlap competitor (e.g., <cycle>). In the OH-PL condition, targets and competitors had a word initial orthographic overlap of two letters so that the nucleus vowel of the first syllable was always spelled similarly but pronounced differently (e.g., <cidre $>$

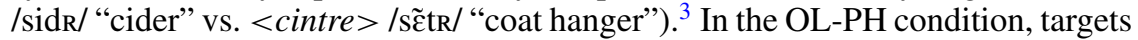
and competitors always had a word-initial phonological overlap of two sounds so that the nucleus vowel of the first syllable was pronounced similarly but spelled differently (e.g., <cidre > /side/ vs. <cycle > /sikl/ "cycle"). Each target (e.g., $<$ cidre $>/$ sidR/) and its competitors (vs. <cintre $>/ \mathrm{s} \tilde{\mathrm{t} t \mathrm{R}} /$ and $<$ cycle $>/ \mathrm{sikl} /$ ) were associated with two distractor words that were orthographically, phonologically, and semantically unrelated.

The two competitors were matched for frequency (Lexique 3; New, Pallier, Ferrand, \& Matos, 2001) as well as possible. The mean frequency of the OH-PL competitors was 43.7 per million and of the OL-PH competitors 47.9 per million. In addition, distractors in each display were matched for frequency with the target, 32.6 and 35.3 per million, respectively. Targets, competitors, and distractors were also matched for written length. ${ }^{4}$ The 20 target word sets are listed in Appendix A. In addition to the target displays, 50 filler displays were constructed. In order to avoid the participants developing test-taking strategies and recognizing the target displays on the basis of formal similarity between the words, 20 of the filler displays had an overlap between the distractor words. In 10 of these filler displays, the distractors had an OH-PL overlap, and in 10 displays, the distractors had an OL-PH overlap. The remaining 30 filler sets comprised four words with no orthographic, phonological, or semantic overlap. In sum, Experiment 1 consisted of 70 trials (20 target word displays, 20 manipulated filler displays, and 30 filler displays).

Each target word was embedded in a French sentence instructing the participant to click on the target word (e.g., "cliquez sur le mot cidre"). These sentences were recorded digitally using the SANAKO Lab100 hardware in the Learning, Age and Bilingualism laboratory at the University of Turku. A female native speaker of French, unaware of the aims of the study, read the sentences in a randomized order with a brief prosodic break before each target word. The mean duration for target words was $616 \mathrm{~ms}$. 


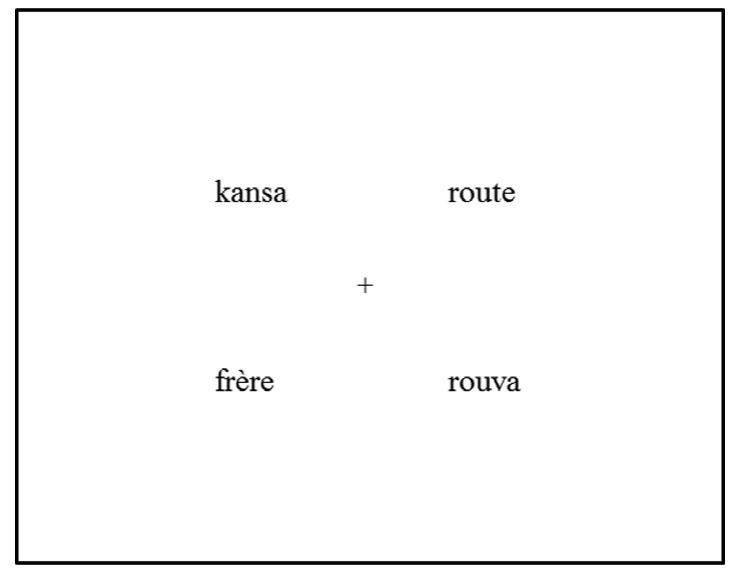

Figure 1. An example of the visual display used in Exp. 1 and Exp. 2 (target: route, competitor: rouva, distractors: kansa \& frère).

Design and procedure. Each trial consisted of responding to the spoken instruction sentence (e.g., "cliquez sur le mot cidre"), by choosing the target word with a mouse click among the four words appearing on the computer screen. The position of each type of word was randomized for each display. For the target word displays, the competitors in the two experimental conditions were counterbalanced between two lists so that each list contained an equal number of OH-PL (10) and OL-PH (10) overlap competitors. The order for the presentation of the 70 trials was randomized for each participant, and the participants were assigned to the two experimental lists in the order of appearance.

Participants' eye movements were monitored using a head-mounted SR EyeLink II eye-tracker (www.sr-research.com) sampling at $500 \mathrm{~Hz}$. Each trial started with drift correction where the participants fixated on a small cross appearing in the center of the screen for the experimenter to accept the gaze accuracy. After that, the spoken instruction to click on the target word was given via headphones. The visual display (see Figure 1) appeared on the screen $200 \mathrm{~ms}$ before the onset of the target word (cf. Huettig \& McQueen, 2007; McQueen \& Viebahn, 2007; Salverda \& Tanenhaus, 2010). As it takes about $200 \mathrm{~ms}$ to program and launch a saccade after a stimulus is presented (Matin, Shao, \& Boff, 1993), this assured that the participants were not able to read the target words and have access to the phonological form via orthography before hearing the targets. The written words were presented in lowercase Times New Roman font being approximately 3 to 4 degrees wide, with the center of each word appearing approximately 8 degrees from the center of the screen (Figure 1).

Before the main experiment, participants were familiarized with the task by presenting a practice block of 10 displays consisting of unrelated words. After that, they were presented with Experiments 1 and 2. The order of the experiments was counterbalanced between participants. 


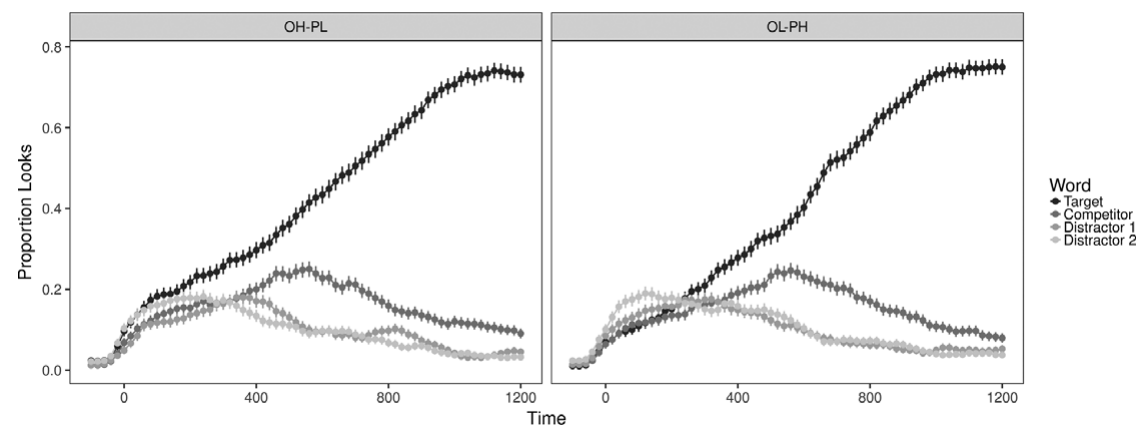

Figure 2. Mean proportion of looks to each type of word in the two experimental conditions in Exp. 1.

\section{Results and discussion of Experiment 1}

Five trials ( $0.5 \%$ of the data) were removed from the analyses because the participants clicked on the competitor word instead of the target word. ${ }^{5}$ The proportion of looks to the targets, to the competitors, and to the distractors was determined for each trial and for each participant by calculating the number of looks to each word in 20-ms time bins. Mean proportions of looks to each type of word in the two experimental conditions for a $1200-\mathrm{ms}$ period starting from target word onset are presented in Figure 2.

Proportions of looks to each type of word do not differ at word onset, but as Figure 2 shows, looks to distractors start to diverge from target and competitor looks in both experimental conditions at about $300 \mathrm{~ms}$ after the onset of the target word. Looks to competitors increase until around $500 \mathrm{~ms}$, and looks to targets increase until reaching the asymptote around $1000 \mathrm{~ms}$ after onset. Therefore, we examined the data more in detail within a time window ending at this latter time point (200-1000 ms after target word onset). The proportions of fixations were logit-transformed for statistical analyses (Fox \& Weisberg, 2011), ${ }^{6}$ providing an unbounded measure in which zero represents $50 \%$ of looks (Barr, 2008).

Visual world eye-tracking data is inherently time-series data and usually presents nonlinearly over time (see Figure 2). In addition, it is possible that the time course interacts with other continuous variables, such as proficiency (cf. Veivo et al., 2016), which may also be nonlinear. We therefore used generalized additive mixed modeling (GAMM; Baayen, Vasishth, Kliegl, \& Bates, 2017; Hastie \& Tibshirani, 1990; Wood, 2006), which does not assume a linear relationship between predictors and the response variable and is capable of modeling interactions between continuous variables (here, time and proficiency; see Baayen et al., 2017; Baayen, van Rij, de Cat, \& Wood, 2018; Veivo et al., 2016). Furthermore, given the time series nature of the data, GAMM also allows for the control of autocorrelation in the data (see, e.g., Porretta, Kyröläinen, van Rij, \& Järvikivi, 2018). Autocorrelation relates to the correlation between data points in a time series; a measurement at time point $t$ is correlated to differing degrees with a measurement at time point 
$t-i$, depending on the lag. Autocorrelation is particularly problematic because it can greatly increase overconfidence of the model estimates.

In order to understand how online target word processing is modulated by proficiency and overlap, we modeled logit transformed looks to the target word as a function of time (200-1000 ms after target onset), proficiency (ranging from A1 to $\mathrm{C} 2$ ), and overlap condition (OH-PL vs. OL-PH). In addition, list and trial were included in the analysis as control variables. Finally, to control for individual variation in looking behavior, we created the variable event. Here, event represents the combination of participant and trial, capturing participants' variable responses to different items in the experiment. Event was included in the model as a random effect, allowing each unique time series to have its own intercept in the model (Baayen et al., 2016; Nixon, van Rij, Mok, Baayen, \& Chen, 2016; Porretta, Tucker, \& Järvikivi, 2016).

It is reasonable to expect that proficiency (a continuous variable) may influence the time course of processing nonlinearly. To allow for this, we used a tensor product (Wood, 2006) for a nonlinear relationship between time and proficiency. Further, also using a tensor product, a difference surface (Baayen, 2010; Wood, 2006) was included for overlap condition. This approach allows for the evaluation of the significance of the factor relative to the interaction of time and proficiency. In this case, the difference surface informs how and where OH-PL is different from the overall effect by adding an additional smoothing parameter on top of the main trend (Zuur, Ieno, Walker, Saviliev, \& Smith, 2009). Finally, trial order was included as a smooth term, and list was included as a parametric term.

The model was fitted to the data through a series of steps in order to assess the contribution of each variable. First, we fitted a full model (i.e., all the predictors, as described above). Second, autocorrelation was estimated from the data ( $\rho=$ 0.895 , indicating a fairly high correlation between subsequent time points), and the model was refitted including this parameter to adjust the confidence of the estimates. Third, we evaluated the contribution of the individual predictors in the model. For this, two criteria were used: the $p$ value of the term (indicating whether a given effect is not zero) and maximum likelihood (ML) score comparison between model variants (indicating whether the inclusion of the predictor improved the fit of the model; Zuur et al., 2009). This process was done iteratively in a backward stepwise fashion until the model contained only predictors that were statistically significant and contributed to the model fit. Trial and the difference surface for overlap condition were removed through the fitting process, indicating that the order of presentation of the targets was not significant, $\chi^{2}(2)=1.017, p=.362$, nor was the type of overlap between targets and competitors, $\chi^{2}(5)=1.182, p=.797$.

ML score comparisons with chi-square tests between variant models justified including proficiency as an input variable, $\chi^{2}(3)=30.192, p<.001$. The resulting model contained the following predictors: event, experimental list, Time $\times$ Proficiency, and explained $30.6 \%$ of the deviance. The statistics for the parametric and smooth terms of the model with the best fit are summarized in Table 2. The significant effect of proficiency over time is depicted in Figure 3.

In interpreting the GAMM results, visual inspection of the figures is essential, perhaps even more so than in other types of data analysis. Figure 3 presents the interaction between proficiency and time as a regression surface, showing that 
Veivo et al.: L1 orthographic information in late L2 learners

Table 2. Generalized additive mixed model with best fit for target looks in Experiment 1: Parametric coefficients and estimated degrees of freedom (Edf), reference degrees of freedom (Ref. $d f$ ), $F$ values, and $p$ values for the tensor product

\begin{tabular}{lcccc}
\hline \hline \multicolumn{1}{c}{ Parametric coefficients } & Estimate & Std. error & $t$ value & $p$ value \\
\hline (Intercept) & -0.262 & 0.080 & -3.252 & .001 \\
Experimental list & -0.360 & 0.113 & -3.190 & .001 \\
\hline Smooth terms & $\mathrm{E} d f$ & Ref. $d f$ & $F$ value & $p$ value \\
\hline Smooth: Items and participants & 436.78 & 1016 & 0.757 & $<2 \mathrm{e}-16$ \\
Tensor: Time, proficiency & 15.48 & 19 & 85.420 & $<2 \mathrm{e}-16$ \\
\hline \hline
\end{tabular}

\section{Looks to Target}

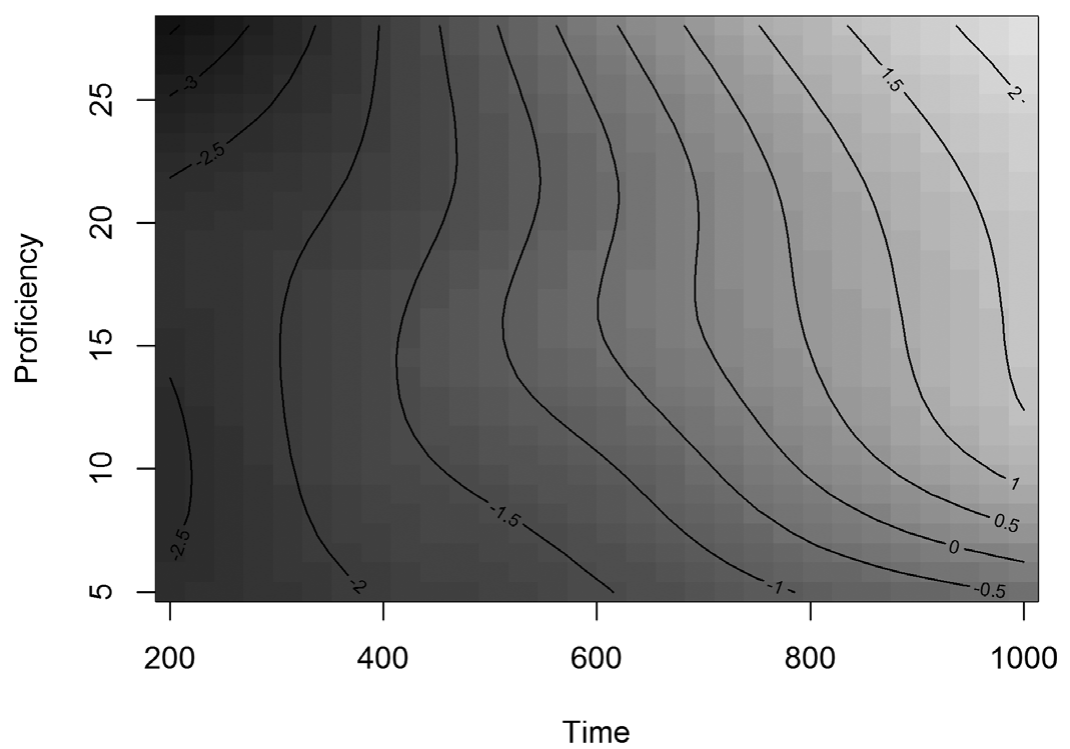

Figure 3. The effect of Proficiency over Time for target looks in Exp. 1.

overall, as time progressed, participants were generally more likely to look at the target. Here darker shades of gray represent fewer looks to the target, whereas lighter shades of gray represent more looks to the target, and the contour lines indicate the rate of change.

More interesting, as proficiency increased, the participants were more likely to look at the target. Lower proficiency learners looked at the targets later than higher proficiency learners. Proficiency especially influenced processing in participants with proficiency scores under 15 (equal to CEFR-levels A1, A2, and B1) and did 
so in a graded fashion. For example, if we follow the time course for participants with proficiency scores 5 and 20, we find that lower proficiency participants were less likely to fixate the targets (between $400 \mathrm{~ms}$ and $600 \mathrm{~ms}$ ). However, we can also see that the effect of proficiency was not linear along the proficiency continuum. This is evidenced by the shape of the contour lines, which indicate a strong effect of proficiency for participants with scores under 15 and little to no effect for participants with scores over 15.

The results of Experiment 1 fail to provide evidence that the OH-PL overlap between targets and within-language competitors delays the mapping between spoken and written forms more than OL-PH overlap. This suggests that when both orthographic and phonological competitors are present at the same time, both orthographic and phonological information is used in the matching process to a similar degree. We will return to this issue in detail in the General Discussion. However, our results confirm that the speed of target identification depends on L2 proficiency in a nonlinear fashion: more proficient L2 listeners fixate the targets faster than less proficient learners, and the influence of proficiency is more pronounced in the lower half of the proficiency scale.

As we were interested in how the L1 modulates L2 performance, we next moved on to investigate the activation of orthographic and phonological information from the participants' L1 in the recognition of L2 word forms in Experiment 2. This experiment was designed to examine the impact of L1 orthography on the mapping process of the L2 at different proficiency levels.

\section{EXPERIMENT 2}

\section{Method}

Participants. Participants were the same as in Experiment $1 .^{7}$ Therefore, the two experiments were presented in a counterbalanced order between the participants.

Materials. As in Experiment 1, the visual displays consisted of four words: the target, the competitor, and two distractor words. Experiment 2 comprised 28 target words. Each French target word (e.g., <paume>/pom/ "palm") was associated with a Finnish competitor with either a OH-PL overlap (e.g., <pauhu>/pauhu/ "roar") or a OL-PH overlap with the target word (e.g., <pommi > /pom:i/ "bomb"). In the OH-PL condition, targets and competitors had a word-initial orthographic overlap of three letters so that the nucleus vowel of the first syllable was always spelled similarly but pronounced differently according to L1 phoneme-grapheme correspondences (cf. $<$ paume $>/$ pom/vs. $<$ pauhu $>/$ pauhu/). ${ }^{8}$ In the OL-PH condition, targets and competitors always had a word-initial phonological overlap of two sounds so that the nucleus vowel of the first syllable was always pronounced as similarly as possible (the vowel systems of the two languages not being the same) but spelled differently (cf. <paume $>/$ pom/ vs. $<$ pommi $>/$ pom:i/). Each target (e.g., <paume >/pom/) and its competitors (e.g., <pauhu>/pauhu/ and $<$ pommi $>$ /pom:i/) were associated with two orthographically, phonologically, and semantically unrelated distractors, one in the L1 and the other in the L2. The visual display therefore always consisted of two words in the L2 (French), the 


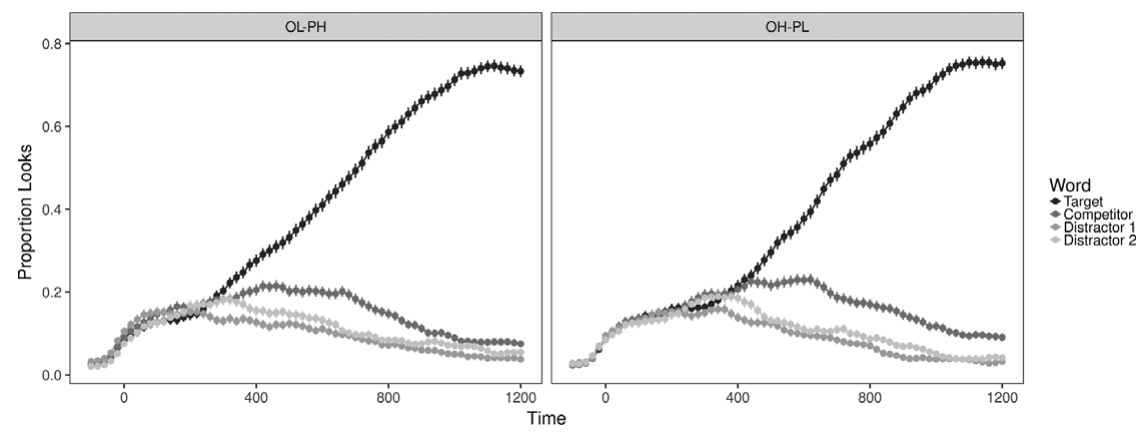

Figure 4. Mean proportion of looks to each type of word in the two experimental conditions in Exp. 2.

target and the first distractor, and of two words in the L1 (Finnish), the competitor and the second distractor. Competitors were matched as well as possible for written frequencies reported in the unpublished Turun Sanomat newspaper lexical database (comprising 22.7 million word tokens) using the WordMill Lexical Search Program (Laine \& Virtanen, 1999). The mean frequency was 12.6 per million for the OH-PL overlap competitors and 29.1 per million for the OL-PH overlap competitors. Distractors were matched for frequency with the target. The mean frequency of the target words was 118.8 per million; the mean frequency of the distractor words was 109.7 per million (101.8 per million for the L1 distractors and 117.6 per million for the L2 distractors). The 28 target word sets are listed in Appendix B. In addition to the target set, we constructed a 28 -item filler set that consisted of four words with no orthographic, phonological, or semantic overlap. In the filler sets, the target and another word were in the L2 (French) and two additional words were in the L1 (Finnish). The procedure for recording the targets was as in Experiment 1. The mean duration of target words was $592 \mathrm{~ms}$.

Design and procedure. The design and procedure were identical to those in Experiment 1.

\section{Results and discussion of Experiment 2}

Before the analyses, 6 trials ( $0.3 \%$ of the data) were removed from the data because the participants erroneously clicked on the competitor word. As in Experiment 1, the proportion of looks to the targets, to the competitors, and to the distractors was determined for each trial and for each participant by calculating the number of looks to each type of word in 20-ms time bins. The mean proportion of looks to each word in the display for $1200 \mathrm{~ms}$, starting from the target word onset, is depicted in Figure 4.

Visual inspection of the plots shows that looks to distractors start to diverge from competitor and target looks at about $300 \mathrm{~ms}$ and that looks to competitors start to decline around $600 \mathrm{~ms}$ after target word onset. Looks to targets increase 
Veivo et al.: L1 orthographic information in late L2 learners

Table 3. Generalized additive mixed model with best fit for target looks in Experiment 2: Parametric coefficients and estimated degrees of freedom (Edf), reference degrees of freedom (Ref. $d f), F$ values, and $p$ values for the tensor products

\begin{tabular}{lrrrr}
\hline \hline \multicolumn{1}{c}{ Parametric coefficients } & Estimate & Std. error & $t$ value & $p$ value \\
\hline (Intercept) & -0.383 & 0.078 & -4.916 & $<.001$ \\
Experimental list & -0.324 & 0.089 & -3.639 & $<.001$ \\
\hline Smooth terms & Edf & Ref. $d f$ & $F$ value & $p$ value \\
\hline Smooth: Items and subjects & 952.730 & 1781.000 & 1.154 & $<2 \mathrm{e}-16$ \\
Tensor: Time, proficiency & 13.355 & 16.871 & 103.105 & $<2 \mathrm{e}-16$ \\
Tensor: Time, proficiency overlap condition & 8.425 & 9.286 & 3.839 & $<.001$ \\
\hline \hline
\end{tabular}

until reaching the asymptote around $1000 \mathrm{~ms}$. As in Experiment 1, the proportions of looks in each 20-ms bin were logit-transformed for statistical analyses to give an unbounded measure.

As in Experiment 1, we examined the time course of target identification more in detail in a time window from $200 \mathrm{~ms}$ until $1000 \mathrm{~ms}$ after the target word onset. Again, we used GAMM, and the model was structured exactly as in the analysis of Experiment 1. The model was fitted using the same steps and procedure as in Experiment 1 . Through this process, an autocorrelation parameter of $\rho=0.895$ was included, and trial was removed from the input variables. ML score comparisons with chi-square tests between variant models supported the inclusion of list, $\chi^{2}$ $(1)=6.599, p<.001$, the difference surface for overlap condition, $\chi^{2}(6)=$ $11.860, p<.001$, and proficiency, $\chi^{2}(6)=27.278, p<.001$, as input variables. The resulting model consisted of random intercepts for event, a parametric term for list, an interaction between time and proficiency, and a difference surface for overlap condition. This final model explains $38 \%$ of the deviance; the estimates for the parametric and smooth terms are summarized in Table 3.

Panel 1 of Figure 5 presents the interaction of proficiency and time as a regression surface. As in the results of Experiment 1, as time progressed, participants were generally more likely to look at the target. Again, lighter gray represent greater likelihood of target looks, while darker gray represents lesser likelihood of target looks, and the contour lines indicate the rate of change. Similar to Experiment 1 , as proficiency increases, the participants were more likely to look at the target; lower proficiency learners were less likely to look at the target over time than higher proficiency learners. However, if we compare the shape of the contour lines in Figures 3 and 5 (Panel 1), we can see that this effect in Experiment 2 is less pronounced than in Experiment 1, affecting primarily the lowest proficiency learners with proficiency scores from 5 to 10 (CEFR levels A1 and A2).

In contrast to Experiment 1, we also observed a significant adjustment due to overlap condition (i.e., significant difference surface), indicating that the Time $\times$ Proficiency surface for OH-PL (Figure 5, Panel 2) deviates significantly from the 

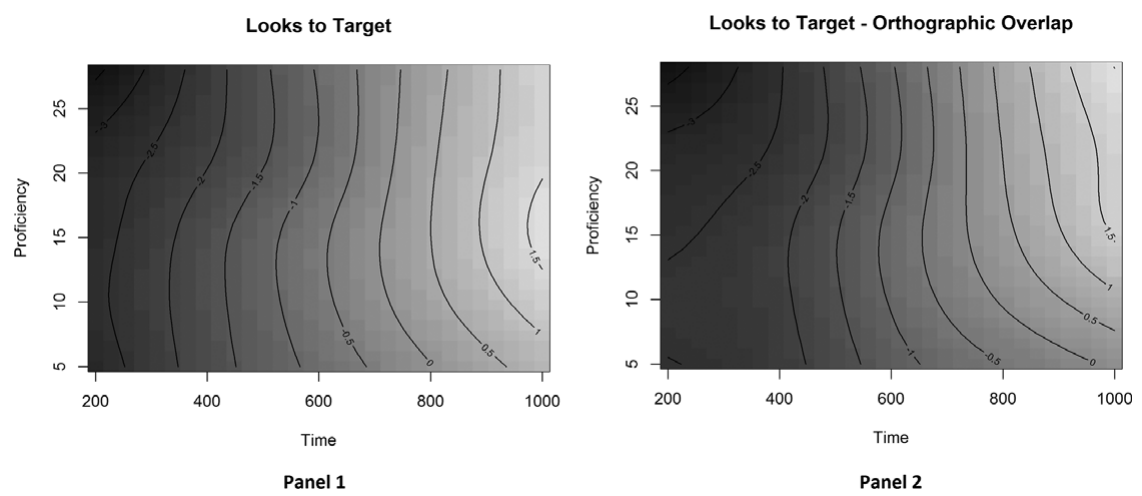

Figure 5. The effect of Proficiency over Time for target looks (Panel 1) and the difference surface for OH-PL Overlap (Panel 2) in Exp. 2.

main Time $\times$ Proficiency surface (Figure 5, Panel 1). Between the two panels we see a greater influence of proficiency in the second half of the time course. As explained above, Panel 1 of Figure 5 presents the effect of proficiency over time for target looks in the whole data. To aid in the visualization of the effect of overlap condition, Panel 2 depicts the same effect but with the difference surface added to show the effect in the OH-PL-condition (e.g., <paume >/pom/ vs. <pauhu> /pauhu/). Compared to Panel 1, Panel 2 shows that, in the second half of the time course, participants with a proficiency score above 15 (CEFR-levels B2, C1, and C2) were more likely to fixate the target, whereas participants with proficiency scores below 15 (CEFR-levels A1, A2, and B1) were less likely to fixate the target. The significant difference surface for overlap $F(8.425,72,249.49)=3.839$, $p<.001$, indicated that this adjustment across proficiency was not zero after approximately $600 \mathrm{~ms}$ after target word onset.

Thus, when presented with orthographic competitors from the participants' L1, higher proficiency learners were more likely to look at the target while lower proficiency learners were less likely to look at the target. In addition, learners in the upper half of the proficiency scale behaved more uniformly than learners in the lower half of the proficiency scale. In other words, lower proficiency learners showed more variation in the speed of finding the targets across proficiency scores.

The results of Experiment 2 indicate that the mapping between L2 spoken and written word forms is influenced by between-language competitors from the participants' L1. This finding is in line with previous findings on language nonselective lexical access in L2 auditory word recognition (e.g., Lagrou, Hartsuiker, \& Duyck, 2011). As in Experiment 1, the effect of proficiency on matching spoken and written word forms was more pronounced in lower proficiency participants. Furthermore, analysis of the time course of activation in the matching process with GAMM revealed an effect of L1 orthographic overlap that appeared $600 \mathrm{~ms}$ after target word onset: compared to the main trend, it was more difficult for the participants in the lower half of the proficiency scale to find the targets (e.g., <paume > /pom/) 
Veivo et al.: L1 orthographic information in late L2 learners

in the presence of OH-PL L1 competitors (e.g., <pauhu> /pauhu/). The effect of proficiency was also more pronounced in the presence of OH-PL L1 competitors for lower proficiency participants in this same time window.

These results suggest that in spoken word identification in late $\mathrm{L} 2$ learners, both orthographically and phonologically similar L1 words are activated early in the recognition process, but later on, orthographic information is activated more than phonological information. In contrast to Veivo and Järvikivi, (2013), we did not find evidence for the effect of L1 orthography depending on proficiency. It is likely that, unlike in masked priming that taps into the early phase of processing, in the kind of matching task used in the present study, lower proficiency learners did not rely on sublexical correspondences of the L1 more than on those of the L2. Instead, we observed significantly more activation for orthographically similar L1 words at all proficiency levels. Taken together, these results speak for an orthographically mediated activation in matching the spoken and written word forms, compatible with the orthographic bias hypothesis presented above.

\section{GENERAL DISCUSSION}

Our objective in the present study was to investigate the impact of orthographic and phonological information in the matching of spoken and written L2 word forms. This was done in the presence of within-language (Experiment 1) and betweenlanguage competitors (Experiment 2). We studied L1 Finnish late learners of L2 French and used the visual world eye-tracking paradigm with printed words as referents. We set out to evaluate the orthographic bias hypothesis, according to which orthographic representations in late L2 learners are more robust than phonological representations. This hypothesis makes the prediction that spoken L2 target words activate mainly orthographic representations, and therefore orthographically similar competitors in the L2 and L1 should delay the mapping between spoken and written L2 word forms more than phonologically similar competitors. Because phonological representations are likely to become more accurate as proficiency increases, proficiency was expected to affect the speed of target identification. For L1 competitors, we predicted that higher proficiency learners might show orthographic effects, whereas lower proficiency learners might rely on L1 sublexical correspondences, which would show as increased activation of phonologically similar L1 competitors.

The results of our within-language experiment (Experiment 1) showed that orthographically and phonologically similar L2 word forms are activated rapidly, around $300 \mathrm{~ms}$ after target word onset. This result is in line with previous visual world studies reporting phonological effects (e.g., Huettig \& McQueen, 2007) and orthographic effects in L1 speakers (Salverda \& Tanenhaus, 2010). The results of our between-language experiment (Experiment 2) showed that spoken L2 words also activated orthographically and phonologically similar word forms in the participants' L1, Finnish.

In the within-language experiment (Experiment 1), competitors with an OH-PL overlap did not delay target identification more than competitors with an OL-PH 
overlap. Written competitors in the OH-PL condition were selected so that the vowel of the nucleus was always pronounced differently from the targets (/sidR/ $<$ cidre $>$ vs. /sẽtR/ < cintre $>$ ), whereas written competitors in the OL-PH condition were always selected so that the vowel of the nucleus was pronounced similarly to the targets $(/ \mathrm{sidR} /<$ cidre $>$ vs. /sikl/ < cycle $>$ ). If the participants had unstable grapheme-phoneme correspondences in the L2, the competitors in the two overlap conditions were not necessarily phonologically different for them. In addition, because the two competitors were allowed to share word-final letters (such as $\langle e\rangle$ ), the competitors may not have been orthographically different enough to produce a significant difference. This result does not necessarily rule out the orthographic bias hypothesis. It is possible that the activation spreads mainly via orthographic representations. In other words, a spoken word like/side/ activates its written counterpart $<$ cidre $>$, which then sends activation to both $<$ cintre $>$ and $<$ cycle $>$. This is likely especially if the learners are not aware of the pronunciation difference between the two written competitors.

In the between-language experiment (Experiment 2), the analysis revealed a nonlinear interaction between time, proficiency, and the type of overlap. When spoken L2 targets like /pom/ < paume $>$ were presented with OH-PL competitors from the participants' L1 (<pauhu> / pauhu/), these competitors delayed target identification significantly compared to the main trend in a time window from $600 \mathrm{~ms}$ to $1000 \mathrm{~ms}$ after target onset for lower proficiency participants. In addition, the effect of proficiency was more prominent in the presence of these OH-PL competitors for these participants in the same time window. Unlike in Experiment 1, the degree of phonological overlap between targets and competitors in Experiment 2 was unambiguous for participants at all proficiency levels, because the competitors were in the L1. According to L1 pronunciation rules, there was always a phonological mismatch between L2 targets and L1 OH-PL competitors. Therefore, spoken L2 words such as /pom/ < paume > could activate OH-PL competitors such as /pauhu/ <pauhu> only via orthographic representations. ${ }^{9}$ As predicted by the orthographic bias hypothesis, orthographic representations are activated significantly more than phonological representations at this relatively late time point.

Unlike we assumed on the basis of previous results (Veivo \& Järvikivi, 2013), lower proficiency learners were not relying on L1 grapheme-phoneme correspondences in Experiment 2, because written L1 competitors that could be pronounced similarly to the targets did not delay the matching. Instead, the delay in target word recognition due to orthographically similar L1 competitors was even more salient for lower proficiency learners. This is in line with the assumption that the orthographic bias would be more prominent in lower proficiency learners and decrease as proficiency increases. It is also possible that the higher proficiency learners were more able to suppress the irrelevant between-language information and that this suppression was enhanced when the orthographic information made it clearer what the unfolding word form would be. This interpretation is in line with the results of Blumenfeld and Marian (2013), which suggest that more efficient cognitive control is associated with reduced cross-linguistic activation in bilinguals in a relatively late phase of lexical competition (633-767 ms). 
Veivo et al.: L1 orthographic information in late L2 learners

Based on previous research (e.g., Mitsugi, 2016; Veivo \& Järvikivi, 2013; Veivo et al., 2016), we assumed that proficiency would influence the speed of the matching process. Our results confirmed this assumption: in both experiments, higher proficiency learners identified the targets significantly faster than lower proficiency learners. This difference in processing speed suggests that lower proficiency learners have less precise phonological representations to base the matching on (cf. Cook et al., 2016). However, the effect of proficiency on the speed of looking at the targets was not linear throughout the proficiency continuum: the lower proficiency learners were not only generally slower in looking at the target than higher proficiency learners but also relatively slower the less proficient they were, unlike learners in the upper half of the proficiency continuum (CEFR-levels B2, C1, and C2) who behaved more homogenously in the task. This suggests that until this point, connections between the modalities develop gradually, but that above this point, they have mostly been acquired.

The results of the present study are discussed above in terms of coactivation orthographic and phonological information in spoken word processing (see, e.g., Grainger et al., 2003). This same principle underlies the structure of the Bilingual Language Interaction Network for Comprehension of Speech (BLINCS; Shook \& Marian, 2013). In BLINCS, different levels of representation are represented by self-organizing maps that structure language input from both languages according to similarity between units. Further, ortholexical and phonolexical levels of representations are shared between both languages and interconnected via bidirectional links. In this respect, the architecture of BLINCS is similar to the interactive activation models of bilingual written word recognition like BIA+ (Dijkstra \& van Heuven, 2002).

To our knowledge, there are no current models of L2 spoken word recognition that would comprise a possibility for interaction between the modalities. The BLINCS model was designed to model spoken word recognition in bilingual speakers, but it could be used to describe the coactivation of orthographic information in spoken word recognition also in late L2 learners. The results of the current study suggest that there are two important proficiency-related features that should be considered in modeling L2 spoken word recognition: the relative strength of ortholexical and phonolexical representations as well as the degree of activation of L1 orthography are different depending on the level of L2 proficiency. Although BLINCS assumes that both languages are known equally well, its architecture based on the self-organizing principle fits well for describing also L2 spoken word recognition. Lower proficiency learners have less experience with L2 word forms, especially in speaking, and this lower frequency in the input causes the phonolexical representations to become weaker, or fuzzier (see Cook et al., 2016), than ortholexical representations.

The results of our Experiment 2 indicate that lower proficiency learners are also less efficient in inhibiting the activation of L1 word forms. The results of Veivo and Järvikivi (2013) suggest that this effect may rise from the sublexical phoneme level. Further, this finding suggests that L2 spoken language processing mechanisms could be qualitatively different at different proficiency levels. In sum, our results show that orthography and L2 proficiency are factors that should be incorporated in any model of L2 spoken word recognition. 
Veivo et al.: L1 orthographic information in late L2 learners

In the present study, we compared the use of orthographic and phonological information in the mapping of spoken and written L2 word forms. Based on studies on the importance of orthographic input in L2 acquisition (e.g., Young-Scholten, 2002), it was hypothesized that there is an orthographic bias in late L2 learners' lexicons with orthographic representations being more robust and accurate than phonological representations. This bias predicts increased orthographic activation in L2 spoken word processing compared to phonological activation. The results of our between-language experiment are compatible with this hypothesis because orthographically similar L1 words delayed the matching process significantly more than phonologically similar L1 words. However, the results of our within-language experiment did not provide straightforward evidence in support of the orthographic bias, and therefore it should be evaluated in subsequent research. Finally, our results suggest that the competences needed for combining phonological and orthographic word forms develop significantly more in the lower half than in the upper half of the proficiency scale. Whether the findings on activation of orthographic information apply to more naturalistic L2 spoken word processing contexts remains a question for future research.

\section{APPENDIX A}

TARGETS AND COMPETITORS IN EXPERIMENT 1

\begin{tabular}{|c|c|c|c|c|c|c|c|c|}
\hline \multicolumn{3}{|c|}{ Target } & \multicolumn{3}{|c|}{ OH-PL competitor } & \multicolumn{3}{|c|}{ OL-PH competitor } \\
\hline ORT & PHON & freq. & ORT & PHON & freq. & ORT & PHON & freq. \\
\hline cidre & $\operatorname{sid} R$ & 3.99 & cintre & sẽtr & 4.86 & cycle & sikl & 5.81 \\
\hline faute & fot & 95.2 & farce & fars & 12.5 & forge & for3 & 8.58 \\
\hline folie & foli & 60.74 & foire & fwar & 15.95 & fauve & fov & 13.4 \\
\hline lent & lã & 64.12 & leçon & ləsว̃ & 48.72 & lampe & lãp & 93.1 \\
\hline lynx & lẽks & 1.22 & lyre & lik & 1.42 & limbe & $1 \tilde{\varepsilon} \mathrm{b}$ & 3.18 \\
\hline maure & $\mathrm{moR}$ & 1.15 & marle & maRl & 1.55 & morve & moRv & 1.96 \\
\hline membre & mãbr & 64.86 & meuble & mœbl & 53.99 & manque & mãk & 37.2 \\
\hline motte & mot & 9.19 & moule & mul & 9.26 & mauve & mov & 17.6 \\
\hline impôt & $\tilde{\varepsilon}$ po & 6.55 & imité & imite & 1.82 & ainsi & $\tilde{\varepsilon} s i$ & 469 \\
\hline foie & fwa & 17.97 & fort & $\mathrm{f} J \mathrm{R}$ & 212.8 & foyer & fwaje & 30.9 \\
\hline saule & sol & 8.65 & sapin & sap $\tilde{\varepsilon}$ & 26.28 & sonné & sone & 3.58 \\
\hline sens & sãs & 217.5 & selon & səlว̃ & 110.9 & sang & sã & 207 \\
\hline serpe & scRp & 4.32 & senti & sãti & 1.76 & saisi & sezi & 3.92 \\
\hline signal & sipal & 23.11 & simple & sẽpl & 148.6 & syrien & $\operatorname{sinj} \tilde{\varepsilon}$ & 6.82 \\
\hline singe & s $\tilde{\varepsilon}_{3}$ & 22.57 & sirop & siRo & 8.18 & sympa & 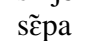 & 7.77 \\
\hline solide & solid & 42.77 & source & suRs & 49.19 & saumon & somว̃ & 4.73 \\
\hline vanter & vãte & 23.24 & vaste & vast & 71.76 & vendu & vãdy & 2.3 \\
\hline mean & & 35.32 & & & 43.69 & & & 47.9 \\
\hline
\end{tabular}




\begin{tabular}{|c|c|c|c|c|c|c|c|c|}
\hline \multicolumn{3}{|c|}{ Target } & \multicolumn{3}{|c|}{ OH-PL-competitor } & \multicolumn{3}{|c|}{ OL-PH-competitor } \\
\hline ORT & PHON & freq. & ORT & PHON & freq. & ORT & PHON & freq. \\
\hline hausse & os & 2.36 & haukka & hauk:a & 17.22 & ostos & ostos & 24.41 \\
\hline renom & Rəñ̃ & 2.43 & renki & renki & 4.89 & rönsy & rønsy & 3.79 \\
\hline roulis & Ruli & 3.04 & rousku & rousku & 3.79 & ruska & ruska & 6.39 \\
\hline renvoi & Rãvwa & 4.8 & rengas & reyas & 44.27 & ranta & ranta & 170.44 \\
\hline horde & oRd & 7.03 & horros & hor:os & 1.54 & orja & orja & 5.77 \\
\hline noix & nwa & 12.23 & noita & noita & 11.15 & nuoli & nuoli & 7.53 \\
\hline sauce & $\operatorname{sos}$ & 13.72 & sauma & sauma & 9.96 & solmu & solmu & 13.88 \\
\hline pince & $\mathrm{p} \tilde{\varepsilon} \mathrm{S}$ & 14.73 & pinja & pinja & 2.03 & päästö & pæ:st $\varnothing$ & 40.18 \\
\hline moulin & 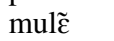 & 19.05 & moukka & mouk:a & 0.79 & multa & multa & 14.58 \\
\hline jouet & उwe & 21.01 & jousi & jousi & 10.93 & suure & su:re & 24.63 \\
\hline souris & suRi & 22.57 & soutu & soutu & 6.87 & surma & surma & 86.65 \\
\hline poupée & pupe & 27.57 & pouta & pouta & 1.45 & puppu & pup:u & 2.38 \\
\hline paume & pom & 35.47 & pauhu & pauhu & 1.98 & pommi & pom:i & 45.51 \\
\hline rumeur & RymœR & 37.97 & rumpu & rumpu & 9.91 & rytmi & rytmi & 26.48 \\
\hline ruine & Ruin & 39.39 & ruiske & ruiske & 1.41 & ryijy & ryijy & 3.61 \\
\hline voile & vwal & 48.31 & voide & voide & 2.42 & vuohi & vuohi & 3.39 \\
\hline ennui & ãnui & 56.62 & enne & enne & 7.00 & anti & anti & 46.96 \\
\hline poil & pwal & 76.01 & poiju & poiju & 2.11 & puomi & puomi & 5.46 \\
\hline neige & n\&3 & 80.88 & neiti & neiti & 5.90 & neste & neste & 66.65 \\
\hline toile & twal & 106.62 & toive & toive & 90.13 & tuomi & tuomi & 36.70 \\
\hline peuple & $\mathrm{p} \varnothing \mathrm{pl}$ & 107.3 & peukku & peuk:u & 0.84 & pöpö & pøpф & 1.67 \\
\hline ventre & vãts & 141.96 & ventti & vent:i & 0.31 & vanne & van:e & 3.22 \\
\hline jardin & 3aRd $\tilde{\varepsilon}$ & 185.81 & jarru & jar:u & 15.90 & sarka & sarka & 13.66 \\
\hline route & Rut & 288.04 & rouva & rouva & 54.19 & rutto & rut:o & 9.47 \\
\hline raison & REZ̃̃ & 308.78 & raivo & raivo & 11.59 & ressu & res:u & 3.79 \\
\hline peur & $\mathrm{p} \emptyset \mathrm{R}$ & 311.69 & peura & peura & 7.36 & pörssi & pørs:i & 43.96 \\
\hline voix & vwa & 612.7 & voima & voima & 477.89 & vuota & vuota & 7.53 \\
\hline nuit & nui & 738.24 & nuija & nuija & 7.49 & nyöri & nyøri & 2.11 \\
\hline mean & & 118.79 & & & 28.98 & & & 25.74 \\
\hline
\end{tabular}

\section{NOTES}

1. A comparison of self-ratings and DIALANG test scores (for DIALANG, see Huhta et al., 2002) in a previous study (Veivo et al., 2015) showed that self-reported proficiency scores based on the CEFR scale correlated highly with DIALANG test results.

2. An L1 speaker control group $(n=24)$ completed Experiment 1 for control purposes. A linear mixed-effect regression analysis of the looks to targets showed that the L1 group was marginally faster than the L2 group in finding the targets, and that the type of overlap in the L1 group was not significant. 
Veivo et al.: L1 orthographic information in late L2 learners

3. This was done because it was not possible to find competitors within the selection criteria with longer orthographic overlap. This is due to the relatively consistent grapheme to phoneme relations of French.

4. To meet the selection criteria, a one-letter difference in length between the words in the display was allowed.

5. In addition, three targets were removed because of an error in choosing the OL-PH competitors.

6. Logit-transformation applies a small adjustment to the values 0 and 1 (using 0.025 and 0.975 , respectively).

7. The same L1 control group who participated in Experiment 1, also participated in Experiment 2 for continuity, but the data were not analyzed in more detail because the participants did not have any knowledge of Finnish, the language of the competitor words.

8. It was not possible to find competitors with equal syllable length in Finnish. It is therefore possible that if the participants knew any one-syllable target words, it may have helped to overrule competitors with two syllables.

9. Because grapheme to phoneme correspondences in Finnish are different from French, there was more variation in the OL-PH competitors in the between-language experiment (Experiment 2) than in the within-language experiment (Experiment 1). Whether this may impact participants to rely more on orthography should be studied in a subsequent experiment contrasting OL-PH competitors from both languages.

\section{REFERENCES}

Allopenna, P. D., Magnuson, J. S., \& Tanenhaus, M. K. (1998). Tracking the time course of spoken word recognition using eye movements: Evidence for continuous mapping models. Journal of Memory and Language, 38, 419-439.

Baayen, R. H. (2008). Analyzing linguistic data: A practical introduction to statistics using R. Cambridge: Cambridge University Press.

Baayen, R. H. (2010). The directed compound graph of English: An exploration of lexical connectivity and its processing consequences. In S. Olson (Ed.), New impulses in word-formation (Linguistische Berichte Sonderheft 17), (pp. 383-402). Hamburg: Buske.

Baayen, R. H., van Rij, J., de Cat, C., \& Wood, S. N. (2018). Autocorrelated errors in experimental data in the language sciences: Some solutions offered by generalized additive mixed models. In. D. Speelman, K. Heylan, \& D. Geeraerts (Eds.), Mixed effects regression models in linguistics (pp. 49-69). Berlin: Springer.

Baayen, R. H., Vasishth, S., Kliegl, R., \& Bates, D. (2017). The cave of shadows: Addressing the human factor with generalized additive mixed models. Journal of Memory and Language, 94, 206-234.

Barr, D. J. (2008). Pragmatic expectations and linguistic evidence: Listeners anticipate but do not integrate common ground. Cognition, 109, 18-40.

Bartolotti, J., Daniel, N. L., \& Marian, V. (2013). Spoken words activate cross-linguistic orthographic competitors in the absence of phonological overlap. Proceedings of the 35th Annual Conference of the Cognitive Science Society (pp. 1828-1832). Austin, TX: Cognitive Science Society.

Bassetti, B. (2006). Orthographic input and phonological representations in learners of Chinese as a foreign language. Written Language and Literacy, 9, 95-114.

Bassetti, B. (2007). Effects of hanyu pinyin on pronunciation in learners of Chinese as a foreign language. In A. Guder, X. Jiang, \& Y. Wan (Eds.), The cognition, learning and teaching of Chinese characters. Beijing, China: Beijing Language and Culture University Press. 
Veivo et al.: L1 orthographic information in late L2 learners

Bassetti, B. (2008). Orthographic input and second language phonology. In P. Thorsten \& M. YoungScholten (Eds.), Input matters in SLA (pp. 191-206). Clevedon: Multilingual Matters.

Bassetti, B., \& Atkinson, N. (2015). Effects of orthographic forms on pronunciation in experienced instructed second language learners. Applied Psycholinguistics, 36, 67-91.

Best, C., \& Tyler, M. (2007). Nonnative and second-language speech perception, commonalities and complementarities. In O.-S. Bohn \& M. Munro (Eds.), Language experience in second language speech learning: In honor of James Emil Flege (pp. 13-34). Amsterdam: Benjamins.

Blumenfeld, H. K., \& Marian, V. (2007). Constraints on parallel activation in bilingual spoken language processing: Examining proficiency and lexical status using eyetracking. Language and Cognitive Processes, 22, 633-660.

Blumenfeld, H. K., \& Marian, V. (2013). Parallel language activation and cognitive control during spoken word recognition in bilinguals. Journal of Cognitive Psychology, 25, 547-567.

Broersma, M., \& Cutler, A. (2011). Competition dynamics of second-language listening. Quarterly Journal of Experimental Psychology, 64, 74-95.

CEFR. (2001). Common European Framework of Reference for Languages: Learning, teaching, assessment. Cambridge: Cambridge University Press.

Cook, S. V., \& Gor, K. (2015). Lexical access in L2: Representational deficit or processing constraint? Mental Lexicon, 10, 247-270.

Cook, S. V., Pandža, N. B., Lancaster, A. K., \& Gor, K. (2016). Fuzzy nonnative phonolexical representations lead to fuzzy form-to-meaning mappings. Frontiers in Psychology, 7, 1-17. doi:10.3389/fpsyg.2016.01345.

Cooper, R. (1974). The control of eye fixation by the meaning of spoken language: A new methodology for the real-time investigation of speech perception, memory, and language processing. Cognitive Psychology, 6, 84-107.

Darcy, I., Daidone, D., \& Kojima, C. (2013). Asymmetric lexical access and fuzzy lexical representations in second language learners. Mental Lexicon, 8, 372-420.

Dijkstra, T., \& van Heuven, W. J. B. (2002). The architecture of the bilingual word recognition system: From identification to decision. Bilingualism: Language and Cognition, 5, 175-197.

Escudero, P., Hayes-Harb, R., \& Mitterer, H. (2008). Novel second-language words and asymmetric lexical access. Journal of Phonetics, 36, 345-360.

Escudero, P., Simon, E., \& Mulak, K. (2014). Learning words in a new language: Orthography doesn't always help. Bilingualism: Language and Cognition, 17, 384-395.

Escudero, P., \& Wanrooij, K. (2010). The effect of L1 orthography on non-native vowel perception. Language and Speech, 53, 343-365.

Fox, J., \& Weisberg, S. (2011). An $\{R\}$ companion to applied regression (2nd ed.). Thousand Oaks, CA: Sage.

Frost, R. (1998). Toward a strong phonological theory of visual word recognition: True issues and false trails. Psychological Bulletin, 123, 71-99.

Frost, R., \& Ziegler, J. C. (2007). Speech and spelling interaction: The interdependence of visual and auditory word recognition. In M. G. Gaskell (Ed.), The Oxford handbook of psycholinguistics (pp. 107-118). Oxford: Oxford University Press.

Grainger, J., Diependaele, K., Spinelli, E., Ferrand, L., \& Farioli, F. (2003). Masked repetition and phonological priming within and across modalities. Journal of Experimental Psychology: Learning, Memory, and Cognition, 29, 1256-1269.

Grainger, J., \& Ferrand, L. (1996). Masked orthographic and phonological priming in visual word recognition and naming: Cross-task comparisons. Journal of Memory and Language, 35, 623647.

Hastie, T., \& Tibshirani, R. (1990). Generalized additive models. Monographs on Statistics and Applied Probability (Vol. 43). Boca Raton, FL: Chapman and Hall/CRC Press.

Hayes-Harb, R., Nicol, J., \& Barker, J. (2010). Learning the phonological forms of new words: Effects of orthographic and auditory input. Language \& Speech, 53, 367-381. 
Veivo et al.: L1 orthographic information in late L2 learners

Huettig, F., \& McQueen, J. M. (2007). The tug of war between phonological, semantic and shape information in language-mediated visual search. Journal of Memory and Language, 57, 460482.

Huettig, F., \& McQueen, J. M. (2011). The nature of the visual environment induces implicit biases during language-mediated visual search. Memory \& Cognition, 39, 1068-1084.

Huettig, F., Rommers, J., \& Meyer, A. S. (2011). Using the visual world paradigm to study language processing: A review and critical evaluation. Acta Psychologica, 137, 151-171.

Huhta, A., Luoma, S., Oscarson, M., Sajavaara, K., Takala, S., \& Teasdale, A. (2002). DIALANG: A diagnostic language assessment system for learners. In J. C. Alderson (Ed.), Common European Framework of Reference for Languages: Learning, teaching, assessment. Case studies (pp. 130-145). Strasbourg: Council of Europe.

Lagrou, E., Hartsuiker, R. J., \& Duyck, W. (2011). Knowledge of a second language influences auditory word recognition in the native language. Journal of Experimental Psychology: Learning, Memory, and Cognition, 37, 952-965.

Laine, M., \& Virtanen, P. (1999). WordMill lexical search program [Computer software]. Turku, Finland: University of Turku, Centre for Cognitive Neuroscience.

Marian, V., \& Spivey, M. (2003a). Competing activation in bilingual language processing: Within- and between-language competition. Bilingualism: Language and Cognition, 6, 97-115.

Marian, V., \& Spivey, M. (2003b). Bilingual and monolingual processing of competing lexical items. Applied Psycholinguistics, 24, 173-193.

Matin, E., Shao, K. C., \& Boff, K. R. (1993). Saccadic overhead: Information-processing time with and without saccades. Perception \& Psychophysics, 53, 372-380.

Mitsugi, S. (2016). Proficiency influences orthographic activations during L2 spoken-word recognition. International Journal of Bilingualism, 22, 199-214.

Mitterer, H. \& Reinisch, E. (2015). Letters don't matter: No effect of orthography on the perception of conversational speech. Journal of Memory and Language, 85, 116-134.

McQueen, J. M., \& Viebahn, M. C. (2007). Tracking the recognition of spoken words by tracking looks to printed words. Quarterly Journal of Experimental Psychology, 60, 661-671.

New, B., Pallier, C., Ferrand, L., \& Matos, R. (2001). Une base de données lexicales du français contemporain sur internet: LEXIQUE. L'Année Psychologique, 101, 447-462.

Nixon, J. S., van Rij, J., Mok, P., Baayen, R. H., \& Chen, Y. (2016). The temporal dynamics of perceptual uncertainty: Eye movement evidence from Cantonese segment and tone perception. Journal of Memory and Language, 90, 103-125.

Porretta, V., Tucker, B., \& Järvikivi, J. (2016). The influence of gradient foreign accentedness and listener experience on word recognition. Journal of Phonetics, 58, 1-21.

Porretta, V., Kyröläinen, A., van Rij, J., \& Järvikivi, J. (2018). Visual world paradigm data: From preprocessing to nonlinear time-course analysis. In I. Czarnowski, R. J. Howlett, \& L. C. Jain. (Eds.), Intelligent Decision Technologies 2017. Proceedings of the 9th KES International Conference on Intelligent Decision Technologies (KES-IDT 2017)—Part II (pp. 268-277). Cham: Springer International Publishing.

Salverda, A. P., \& Tanenhaus, M. K. (2010). Tracking the time course of orthographic information in spoken-word recognition. Journal of Experimental Psychology: Learning, Memory, and Cognition, 5, 1108-1117.

Shook, A., \& Marian, V. (2013). The bilingual language interaction network for comprehension of speech. Bilingualism: Language and Cognition, 16, 304-324.

Showalter, C. E., \& Hayes-Harb, R. (2013). Unfamiliar orthographic information and second language word learning: A novel lexicon study. Second Language Research, 29, 185-200.

Showalter, C. E., \& Hayes-Harb, R. (2015). Native English speakers learning Arabic: The influence of novel orthographic information on second language phonological acquisition. Applied Psycholinguistics, 36, 23-42. 
Veivo et al.: L1 orthographic information in late L2 learners

Simon, E., Chambless, D., \& Kickhöfel Alves, U. (2010). Understanding the role of orthography in the acquisition of a non-native vowel contrast. Language Sciences, 32, 380-394.

Spivey, M. J., \& Marian, V. (1999). Cross talk between native and second languages: Partial activation of an irrelevant lexicon. Psychological Science, 10, 281-284.

Taft, M., Castles, A., Davis, C., Lazendic, G., \& Nguyen-Hoan, M. (2008). Automatic activation of orthography in spoken word recognition: Pseudohomograph priming. Journal of Memory and Language, 58, 366-379.

Tanenhaus, M. K., Spivey-Knowlton, M. J., Eberhard, K. M., \& Sedivy, J. C. (1995). Integration of visual and linguistic information in spoken language comprehension. Science, 268, 1632-1634.

Veivo, O., \& Järvikivi, J. (2013). Proficiency modulates early orthographic and phonological processing in L2 spoken word recognition. Bilingualism: Language and Cognition, 16, 864-883.

Veivo, O., Järvikivi, J., Porretta, V., \& Hyönä, J. (2016). Orthographic activation in L2 spoken word recognition depends on proficiency: Evidence from eye-tracking. Frontiers in Psychology. 27 July 2016. doi:10.3389/fpsyg.2016.01120

Veivo, O., Suomela-Salmi, E., \& Järvikivi, J. (2015). Orthographic bias in L3 lexical knowledge: Learner-related and lexical factors. Language, Interaction and Acquisition, 6, 271-294.

Ventura, P., Morais, J., Pattamadilok, C., \& Kolinsky, R. (2004). The locus of the orthographic consistency effect in auditory word recognition. Language and Cognitive Processes, 19, 57-95.

Wood, S. N. (2006). Generalized additive models: An introduction with R. Boca Raton, FL: Chapman \& Hall/CRC Press.

Young-Scholten, M. (2002). Orthographic input in L2 phonological development. In P. Burmeister, T. Piske, \& A. Rohde (Eds.). An integrated view of language development: Papers in honor of Henning Wode (pp. 263-279). Trier: Wissenschaftlicher Verlag Trier.

Young-Scholten, M., \& Langer, M. (2015). The role of orthographic input in second language German: Evidence from naturalistic adult learners' production. Applied Psycholinguistics, 36, 93-114.

Ziegler, J. C., \& Ferrand, L. (1998). Orthography shapes the perception of speech: The consistency effect in auditory word recognition. Psychonomic Bulletin \& Review, 5, 683-689.

Zuur, A., Ieno, E., Walker, N., Saveliev, A., \& Smith, G. (2009). Mixed effects models and extensions in ecology with $R$. New York: Springer. 